\title{
Kitchen Range Oven Enabled One-tube RT-LAMP for RNA Detection at Home - A Potential Solution for Large-scale Screening of COVID-19
}

$$
\text { Yu Lei } i^{1,2 *}
$$

${ }^{1}$ Department of Chemical and Biomolecular Engineering, University of Connecticut, Storrs, CT 06269, USA

2Department of Biomedical Engineering, University of Connecticut, Storrs, CT 06269, USA

${ }^{*}$ Corresponding Author: Tel.: +1 860486 4554; fax: +1 8604862959

Email address: yu.lei@uconn.edu 


\section{Abstract}

Rapid, low-cost, and user-friendly molecular diagnostic methods are prerequisite to address the outbreaks of infectious diseases. Especially during the outbreak of COVID19 pandemic, there is an urgent need to build the global testing capacity up to 100 -fold above what is achievable with current standard approaches. However, current gold standard methods such as RT-PCR and isothermal PCR (e.g., RT-LAMP), which are routinely conducted in laboratories, suffer from limit capacity due to the requirement of special equipment, multiple sample handling steps, and/or the need of skilled personnel. In this study, a kitchen Range Oven enabled RT-LAMP was conducted at a residential home without sacrificing the performance in RNA detection. In addition, one-step, closedtube RT-LAMP for the detection of target RNA in the oven was accomplished by preloading sample collection solution and RT-LAMP reaction reagents into the bottom and cap cavity of PCR tube, respectively. After the addition of target RNA into sample collection solution through either swab swirling or direct pipetting, a flip-and-swing enabled mixing of sample solution and RT-LAMP reaction reagents was conducted first, followed by RT-LAMP detection at a constant temperature in pre-heated oven. The RNA positive sample can be obviously differentiated from the RNA negative sample through both naked-eye based turbidity detection and fluorescence detection under UV light. In conjunction with the user-friendly one-step, closed-tube concept, this study indicates that it is feasible to run RT-LAMP at home using oven with minimum involvement of end-users, thus offering an excellent molecular detection platform, which has the potential to boost the detection capacity for any nucleic acid target. It could be a potential solution for largescale screening of COVID-19 in short time as the tests can be conducted by residents at home, without the need of well-trained health caregivers and capacity limitation.

\section{Key words:}

Range oven, RT-LAMP, One-tube, RNA detection, closed-tube, Home 


\section{Introduction}

Since 2000, we have already witnessed the outbreaks of several pandemics, including Severe acute respiratory syndrome (SARS, 2002-2004), Influenza A virus H1N1 (20092010), Middle East respiratory syndrome (MERS-CoV, 2012), Ebola virus disease (20132016), and Zika virus (2015-2016). More recently, there is an ongoing pandemic of coronavirus disease 2019 (COVID-19), an infectious disease caused by severe acute respiratory syndrome coronavirus 2 (SARS-CoV-2). Up to date, more than 5 million cases are confirmed in over 200 countries, resulting in over 300,000 deaths worldwide. To fight and contain the outbreaks of pandemics, rapid, accessible, and accurate diagnostic testing with high screening capacity is highly demanded. Currently, diagnosing virus infections mainly relies on two major methodologies: Reverse Transcription Quantitative Polymerase Chain Reaction (RT-qPCR) and serological immunoassays that detect viralspecific antibodies ( $\lg M$ and $\lg G$ ) or antigens. Although $\lg G / \lg M$ serological lateral flow tests offer some advantages over RT-qPCR such as low cost, scalability, user friendliness, and fast results, its low sensitivity and high false-alarm rate greatly limit it to be used as a standard method for diagnosis purpose, rather than identifying the infection history of a person. Currently, RT-PCR test is used as a gold standard to diagnose virus infection through the detection of the presence of viral nucleic acids. Taking COVID-19 as an example, RT-PCR, approved by US Centers for Disease Control and Prevention (CDC), has been widely applied in COVID-19 diagnosis. However, current laboratory-based RTPCR test for SARS-COV-2 suffers from limit testing capacity, which is of paramount importance in addressing COVID-19 pandemic (or any other pandemic) in a timely manner. In order to build the U.S. capacity for SARS-CoV-2 testing up to 100-fold above what is achievable with standard approaches, new solutions are highly demanded to circumvent current limitations and improve current SARS-CoV-2 testing capacity. Consequently, isothermal PCR such as Loop-mediated isothermal amplification (LAMP) have been attracting more and more attention recently.

LAMP assay ${ }^{1}$ is a sturdy innovative isothermal gene amplification technique emerging as a simple rapid diagnostic method for detection and identification of bacterial and viral pathogens. It is extremely appropriate for applications in point-of-care or low resource 
settings. ${ }^{2-12}$ Compared to conventional PCR and real-time PCR, LAMP amplification takes place at a single temperature and thus there is no need of a thermal cycler. Also, LAMP has the advantages of reaction simplicity and higher amplification efficiency. The most innovative and unique property of LAMP is the ability to amplify non-denatured DNA. Thus, LAMP technique eliminates the heat denaturation step for DNA synthesis used in PCR, and relies instead on auto-cycling strand displacement DNA synthesis achieved by a DNA polymerase with strand displacement activity along with two forward and backward inner primers and two outer primers that recognize six separate regions within a target DNA sequence. The specificity of the LAMP amplification is directly attributed to the sets of primers spanning distinct sequences of the target gene that are being used for amplification. Another important feature of LAMP is the color or turbidity change, which is visible to the naked eye and results can be obtained in one hour at a constant set temperature. One other surprising advantaged discovered about this technique is its ability to amplify gene in a poorly or non-processed sample, eliminating the DNA extraction step. ${ }^{13,14}$

To extend LAMP from DNA diagnosis to RNA diagnosis as well as to realize rapid and multiplexed detection, several improvements were added to the LAMP protocol, since its discovery, to develop different methods, including reverse transcription LAMP (RT-LAMP), Six-primer (loop primer) method and Multiplex LAMP. In RT-LAMP, the genetic material targeted is RNA instead of DNA. In the same reaction tube, a reverse transcriptase is included in the reaction mixture to synthesize cDNA template from RNA and this CDNA is finally used in the LAMP reaction. Such step can also be realized using a single enzyme possessing both reverse transcriptase and DNA polymerase activities. This assay has been successfully used in detection of many RNA viruses. ${ }^{6-8}$ LAMP uses a set of four primers. In loop primer method another additional primers (the loop primers) can also be designed to anneal the loop structure in LAMP to enhance the performance. ${ }^{15} \mathrm{~A}$ multiplex LAMP (mLAMP) assay is also developed for simultaneous detection of two or more pathogens in the same reaction tube (using species specific primers of target gene sequences totaling eight primers or more), by amplifying their respective nucleic acid templates. ${ }^{1,5,16,17}$ LAMP technique proves that it is a powerful and ideal technique in molecular biology field and LAMP diagnostic kits are currently available for clinical 
diagnosis of some infectious diseases, which reflects the quality and usefulness of this technique. However, most of LAMP or RT-LAMP tests are run in advanced laboratories by skilled personnel, which greatly limits its test capacity and field applicability. Up to date, home-use low-cost RT-LAMP is not available. However, if successfully deployed, it could significantly boost the test capacity of nucleic acid-based molecular diagnosis and potentially allow the tests of a large population within one day, because it does not require the skilled personnel to run the tests in well-equipped laboratories.

In this study, we report a kitchen Range oven enabled one-tube RT-LAMP for RNA detection at a residential home. As we do not have access to COVID-19 viral RNA, we use RNA positive control sample and its corresponding LAMP primers provided by the supplier of LAMP kits in our proof-of-concept and demonstration. We further validate that one-step, closed-tube RT-LAMP with minimum involvement of the end-user can be realized by pre-loading concentrated RT-LAMP reaction reagents into the cap cavity of PCR tube, while the sample collection solution was pre-loaded to the bottom of PCR tube, in conjunction with a simple flip-and-swing enabled sample/reagents mixing step after addition of target RNA. The RNA detection of RT-LAMP in an oven was realized through both naked-eye based turbidity detection and fluorescence detection under UV light. The developed method could play an important role in battling COVID-19 and other pandemics of infectious diseases.

\section{Materials and Methods}

\subsection{Materials}

LavaLAMPTM RNA component kit with SYBR Green dye was purchased from Lucigen Corporation (Middleton, WI). Kitchen Range (brand name: MAYTAG) was bought from Sears. Isotemp vacuum oven (Model 281A) was purchased from Fisher Scientific. Autoclaved DI water was used as nuclease-free water.

\subsection{Kitchen range oven enabled RT-LAMP assay}

The "Keep Warm" function of MAYTAG Range oven was used to set the temperature of $155^{\circ} \mathrm{F}\left(\sim 68.33^{\circ} \mathrm{C}\right)$. As temperature control of Range oven has a minimum increment of $5^{\circ} \mathrm{F}$, the temperature set of $155^{\circ} \mathrm{F}$ is the most accurate one close to the optimal RT- 
LAMP temperature of $68{ }^{\circ} \mathrm{C}$, suggested by the supplier. To run RT-LAMP in kitchen Range Oven, the target RNA positive and negative samples were prepared by following the instruction of LavaLAMPTM RNA component kit provided by the supplier, except that $10 \mathrm{mM}$ dNTP mix was used to replace $25 \mathrm{mM}$ dNTP mix (not available in our lab) in the recipe. The RNA positive control in LavaLAMPTM RNA component kit was used as the analog of viral RNA for proof-of-concept in this study. The use of such analogue does not sacrifice the representativity of this study, and thus the conclusion obtained remains the same if being extended to the detection of other RNA targets. After the preparation of RNA positive and negative samples, both samples were then placed in pre-heated Range Oven to carry our RT-LAMP amplification at $155^{\circ} \mathrm{F}\left(\sim 68.33^{\circ} \mathrm{C}\right)$. After 30 min reaction, the samples were taken out for naked-eye based turbidity detection and fluorescence detection under UV light of $254 \mathrm{~nm}$ (the only UV light we have can excite SYBR dye). RTLAMP products can be stored in a freezer of home-use refrigerator for long-term storage if necessary.

\subsection{One-step, closed-tube RT-LAMP assay in an oven (only requiring the end-user to open the tube once for loading the sample at the beginning)}

To enable one-step, closed-tube RT-LAMP in an oven, the sample collection solution and RT-LAMP reaction reagents were prepared in the same PCR tube but stored in different locations. To achieve this unique design, all necessary RT-LAMP reaction reagents, including 10X LavaLAMP TM RNA Buffer (2.5 $\mu \mathrm{L})$, LavaLAMP TM RNA Enzyme $(2.5 \mu \mathrm{L})$, dNTPs mix $(0.8 \mu \mathrm{L})$, Magnesium Sulfate $(1.25 \mu \mathrm{L})$, RNA Positive Control LAMP Primer Mix $(2.5 \mu \mathrm{L})$, and Green Fluorescent Dye $(1 \mu \mathrm{L})$, were pre-loaded into the cap cavity of a PCR tube, while sample collection solution or nuclease-free $\mathrm{H}_{2} \mathrm{O}(14.95 \mu \mathrm{L})$ was loaded into the bottom of the same PCR tube, thus separating them from each other. To mimic the real operation during the detection of viral RNA, the target RNA was added into sample collection solution through either swab swirling or direct pipetting, and then the cap of the PCR tube was gently closed. Both solutions were still in their original places without mixing (or without contacting with each other) due to the small volume of liquid used as well as the strong adhesive force between liquid and plastic surface of PCR tube. To mix the sample collection solution in the tube bottom with the RT-LAMP reaction 
reagents in the cap cavity, the PCR tube was held tightly and flipped vertically, and then swung quickly with sudden stop of the swinging motion. Consequently, the centrifuge-like force moved the sample collection solution to the cap and mixed it with RT-LAMP reaction reagents. The same procedure was repeated to move the mixed solution back to the bottom of PCR tube. After flip-and-swing enabled mixing, the RT-LAMP reaction mixture is ready for oven-enabled isothermal amplification. During the detection, the positive and negative samples were taken out at different time points for end-point assay through both turbidity and fluorescence under UV light. After assay at each time point, the samples were placed back into the oven for continuous amplification.

\section{Results and discussion}

To develop home-use LAMP or RT-LAMP based molecular diagnostic method for the detection of viruses and pathogens, there are several necessary components besides commercially available RT-LAMP (or LAMP) reaction reagents such as maintaining a constant temperature at $62 \sim 72{ }^{\circ} \mathrm{C}$ for designed LAMP (depending on the optimal LAMP temperature), minimum involvement of the end-user (preferably only one involvement of loading the sample), and convenient visual detection. Although common equipment and kits used in research laboratory (e.g., water bath, hotplate, RNA extraction kits, and fluorescence detector) can easily realize isothermal PCR, they are typically not available at residential homes. In addition, multiple operation steps developed for laboratorial operation are not suitable for residential use.

To satisfy the aforementioned requirement for running RT-LAMP at home, we conducted a proof-of-concept test using commercial LavaLAMPTM RNA component kit. In this kit, a positive control RNA and its LAMP primers are provided. The optimal operation temperature of the designed LAMP primers is $68{ }^{\circ} \mathrm{C}$, according to the supplier's instruction manual. Table 1 shows the RT-LAMP reaction mixture components used in our tests, following the protocol provided by the supplier. It is worth noting that as we do not have $25 \mathrm{mM}$ dNTP Mix as suggested by the supplier, we replace it with $10 \mathrm{mM}$ dNTP Mix without sacrificing its performance. Figure 1 shows the overall concept of ovenenabled one-step, closed-tube RT-LAMP at home with minimum involvement of the enduser. 
Table 1. Experimental setup of RT-LAMP reactions

\begin{tabular}{|c|c|c|}
\hline & Positive & Negative Control \\
\hline Component & Amount $(\mu \mathrm{L})$ & Amount $(\mu \mathrm{L})$ \\
\hline Nuclease-free $\mathrm{H}_{2} \mathrm{O}$ & 14.95 & 14.95 \\
\hline 10X LavaLAMP TM RNA Buffer & 2.5 & 2.5 \\
\hline LavaLAMP TM RNA Enzyme & 1.0 & 1.0 \\
\hline dNTP Mix, 10 mM & 0.8 & 0.8 \\
\hline Magnesium Sulfate, 100 mM & 1.25 & 1.25 \\
\hline RNA Positive Control LAMP & 2.5 & 2.5 \\
\hline Primer Mix & & 1.0 \\
\hline Green Fluorescent Dye & 1.0 & $1.0\left(\mathrm{H}_{2} \mathrm{O}\right)$ \\
\hline Target RNA & 1.0 (RNA positive sample) & 25.0 \\
\hline Total Volume & 25.0 & \\
\hline
\end{tabular}

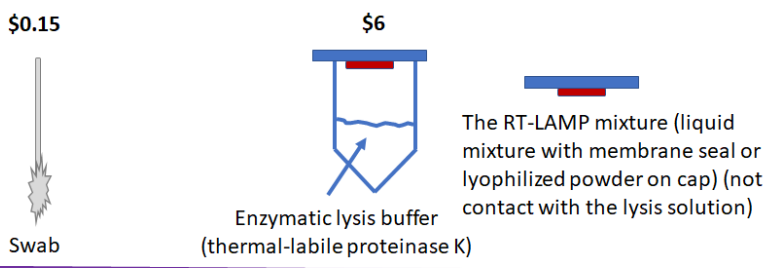

Procedure (estimated total time: $20 \sim 50 \mathrm{~min}$, depending on the concentration of virus RNA or DNA):

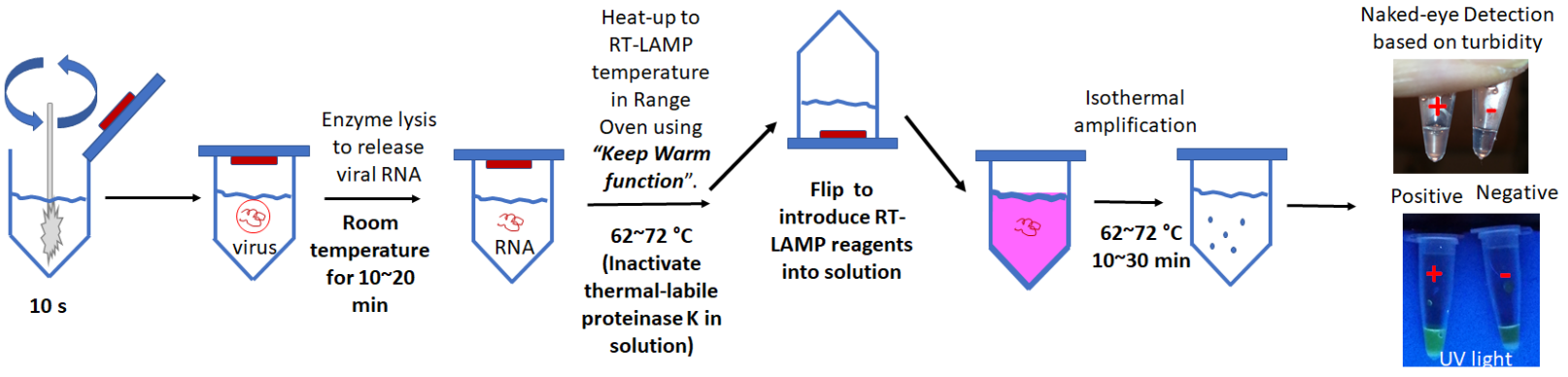

Figure 1. Schematic drawing of the required supplies and the simple one-step, closed-tube procedure for home-use nucleic acid detection with minimum involvement of the end-user (RNA target used as an example).

\subsection{Using kitchen Range Oven to set the right temperature for running RT-LAMP}

The optimum temperature for above RT-LAMP reaction is $68{ }^{\circ} \mathrm{C}$. To realize this temperature, we first used Range Oven's "Keep Warm" function to set the temperature of $155^{\circ} \mathrm{F}\left(\sim 68.33^{\circ} \mathrm{C}\right)$. It is worth noting that "Bake" function of Range Oven has the lowest setting temperature of $170^{\circ} \mathrm{F}\left(\sim 76.7^{\circ} \mathrm{C}\right)$, which is too high for regular LAMP. Its "Keep 
Warm" function (e.g., MAYTAG Range) has the lowest setting temperature of $145^{\circ} \mathrm{F}$ $\left(\sim 62.8^{\circ} \mathrm{C}\right)$ with an increment of $5^{\circ} \mathrm{F}$. As shown in Figure 2, we can set the right constant temperature for running RT-LAMP $\left(155^{\circ} \mathrm{F}\right.$ or $\left.68.33^{\circ} \mathrm{C}\right)$.

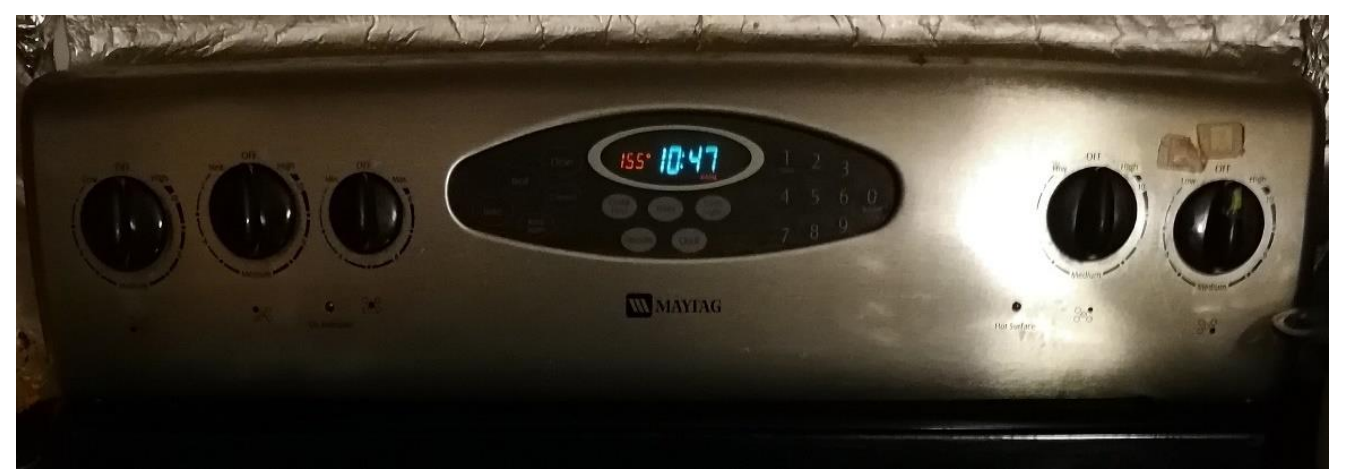

Figure 2. Using kitchen Range Oven's "Keep Warm" function to maintain LAMP-required constant temperature.

\subsection{Running one-tube RT-LAMP in kitchen Range Oven}

To test if kitchen Range Oven (Brand name: MAYTAG in the house of the author) can be used as a reliable heating source to run RT-LAMP, $25 \mu \mathrm{L}$ RT-LAMP reaction mixture with target RNA (positive) and without target RNA (negative) were prepared following the recipe in Table 1. Per the communication with the supplier of Lucigen, the RNA control template in the LavaLAMPTM RNA Component Kit contains 30,000 copies/ $\mu \mathrm{L}$. Therefore, RNA positive sample tested in this experiment has target RNA concentration of 1,200 copies per reaction. Both samples were then placed into kitchen Range Oven, which was pre-warmed to $155^{\circ} \mathrm{F}\left(\sim 68.33^{\circ} \mathrm{C}\right)$ for RT-LAMP test. After 30 min reaction, the samples were taken out for both naked-eye detection through turbidity and fluorescence detection under UV light. As shown in Figure 3, RNA positive sample was rapidly amplified with the production of numerous nucleic acids, which can intercalate fluorescent reporters (SYBR Green) to show enhanced green fluorescence under UV light. If excited under a wavelength closer to SYBR Green excitation wavelength (e.g., blue light), the green fluorescence signal would be much stronger. In addition, a large number of pyrophosphate ions, which were released and accumulated in solution during DNA polymerization, reacted with $\mathrm{Mg}^{2+}$ to form white precipitate of magnesium pyrophosphate. Consequently, the reaction solution became turbid, which is visible to naked eye (Figure 
3). Although the temperature of Range Oven may fluctuate and its temperature control is not as accurate as high-resolution temperature-control equipment used in the research laboratory, the RNA positive sample can still be easily differentiated from RNA negative sample. In addition, air-based heating in the oven typically has a poorer stability than water-bath based heating used in the laboratory. However, the result indicates that it does not affect the RT-LAMP performance significantly. This study corroborates that RT-LAMP can be accomplished using Range Oven, even under the temperature fluctuation. It provides solid ground for the home-use RT-LAMP concept for nucleic acid detection.

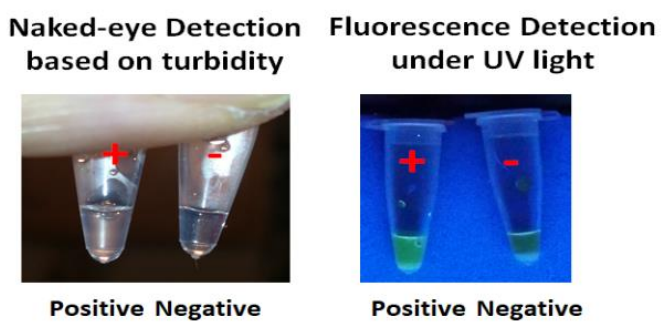

Figure 3. Using kitchen Range Oven's "Keep Warm" function to run RT-LAMP at home and the visual detection of positive sample through turbidity and fluorescence after 30 min reaction.

\subsection{Realizing one-step, closed-tube RT-LAMP design (only requiring the end-user to open the tube once for loading the sample at the beginning)}

To mimic real situation and realize one-step, closed-tube RT-LAMP with the minimum involvement of the end-user at home, following test was conducted to validate the concept. As shown in Table 2, we first added 10X LavaLAMP ${ }^{\text {тM }}$ RNA Buffer $(2.5 \mu \mathrm{L})$, LavaLAMP ${ }^{\text {тM }}$ RNA Enzyme $(2.5 \mu \mathrm{L})$, dNTPs mix $(0.8 \mu \mathrm{L})$, Magnesium Sulfate $(1.25 \mu \mathrm{L})$, RNA Positive Control LAMP Primer Mix $(2.5 \mu \mathrm{L})$, and Green Fluorescent Dye $(1 \mu \mathrm{L})$ into the cap cavity of the PCR tube, while adding Nuclease-free $\mathrm{H}_{2} \mathrm{O}(14.95 \mu \mathrm{L})$ into PCR tube, as shown in Figure 4. (Note: the mixture in the cap can be lyophilized as powder or used as liquid with a sealing membrane). To mimic the positive sample, RNA target was loaded into the $\mathrm{H}_{2} \mathrm{O}$ which can be realized using either swab swirling or direct pipetting (Figure 4). For the negative control, only $\mathrm{H}_{2} \mathrm{O}$ was loaded. Due to the small size of PCR tubes, the strong adhesive force between the liquid and plastic surface of PCR tube holds water at the bottom and concentrated RT-LAMP reaction reagents in the cap, respectively. After the gentle close of the cap, the PCR tube can be vertically flipped without observing the 
movement of liquid. In order to mix the water sample in the bottom of PCR tube with the concentrated RT-LAMP reaction reagents pre-loaded in the cap cavity of PCR tube, we flipped the PCR tube first, held the tube tightly, and then swung the tube with sudden stop of the swinging motion. Such moment forces the water sample to move from the bottom to the cap, thus mixing the collected sample with the RT-LAMP reaction reagents in the cap. After mixing, we flipped the tubes again and repeated the same procedure to move the reaction mixture back to the bottom of PCR tube. This operation can be repeated several times in order to achieve good mixing effect. The whole process is presented in Figure 4. The flip-and-swing enabled mixed samples are then ready for subsequent RTLAMP in the oven.

Table 2. One-step, closed-tube RT-LAMP experimental setup

\begin{tabular}{|c|c|c|c|}
\hline & & Positive & $\begin{array}{c}\text { Negative } \\
\text { Control }\end{array}$ \\
\hline & Component & Amount $(\mu \mathrm{L})$ & Amount $(\mu \mathrm{L})$ \\
\hline $\begin{array}{l}\text { Solution added to the } \\
\text { bottom of PCR tube } \\
\text { (Sample collection } \\
\text { solution) }\end{array}$ & Nuclease-free $\mathrm{H}_{2} \mathrm{O}$ & 14.95 & 14.95 \\
\hline \multirow{6}{*}{$\begin{array}{c}\text { RT-LAMP Reagents added } \\
\text { to the cap cavity of PCR } \\
\text { tube }\end{array}$} & 10X LavaLAMP TM RNA Buffer & 2.5 & 2.5 \\
\hline & LavaLAMP TM RNA Enzyme & 1.0 & 1.0 \\
\hline & dNTP Mix, $10 \mathrm{mM}$ & 0.8 & 0.8 \\
\hline & Magnesium Sulfate, $100 \mathrm{mM}$ & 1.25 & 1.25 \\
\hline & $\begin{array}{l}\text { RNA Positive Control LAMP Primer } \\
\text { Mix }\end{array}$ & 2.5 & 2.5 \\
\hline & Green Fluorescent Dye & 1.0 & 1.0 \\
\hline \multirow[t]{2}{*}{$\begin{array}{l}\text { Will be added to water (or } \\
\text { sample collection } \\
\text { solution) in the tube using } \\
\text { swab swirling or direct } \\
\text { pipetting }\end{array}$} & Target RNA & $\begin{array}{l}1.0 \text { (RNA } \\
\text { positive } \\
\text { sample) }\end{array}$ & $1.0\left(\mathrm{H}_{2} \mathrm{O}\right)$ \\
\hline & Total Volume & 25.0 & 25.0 \\
\hline
\end{tabular}




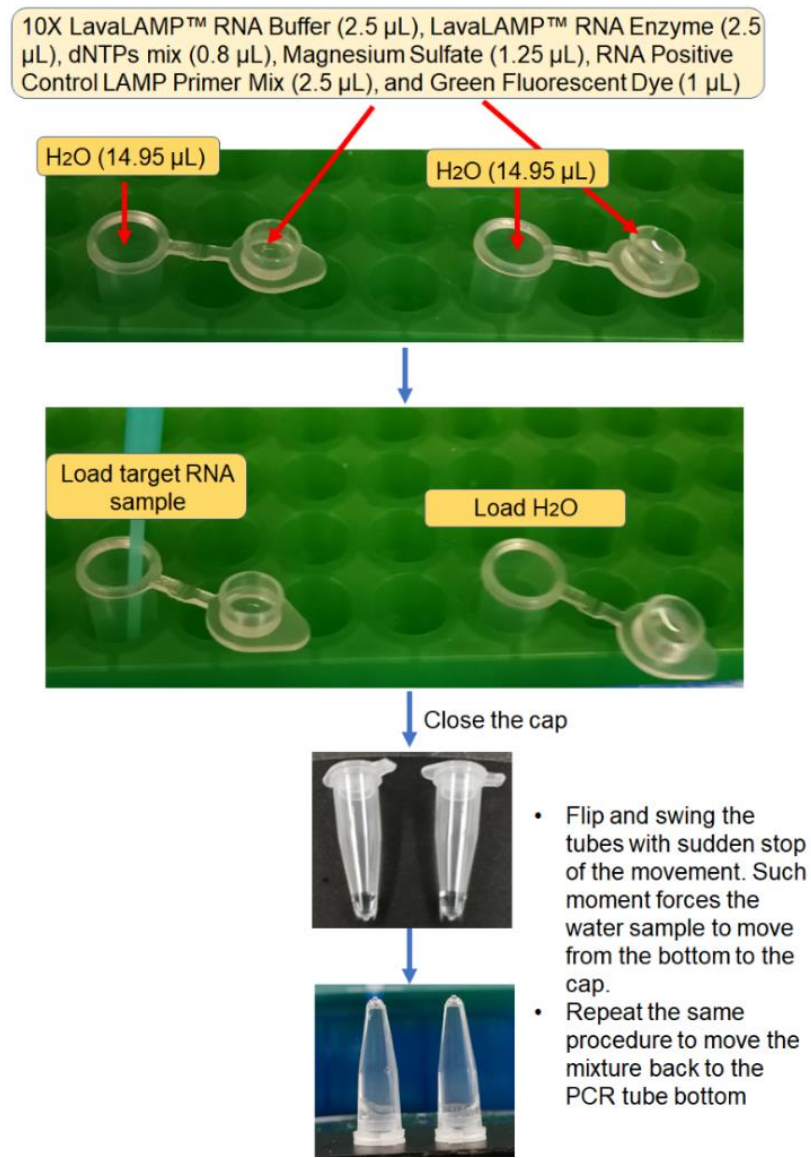

Figure 4. The one-step, closed-tube RT-LAMP concept through flip-and-swing enabled mixing of sample collection solution and RT-LAMP reaction reagents.

\subsection{Running one-step, closed-tube RT-LAMP in oven}

To expand the study to other type of oven with poor temperature control, we employed a vacuum oven (Figure $5 \mathrm{~A}$ ) without a digital temperature control function in RT-LAMP test. This oven only has a knob to control heating with a scale from 0 to 20 . The oven temperature was pre-set and adjusted using a thermometer before placement of one-step, closed-tube RT-LAMP samples prepared in Section 3.3. To simulate the real operation, the as-prepared target RNA positive sample and negative sample were maintained at room temperature for 10-20 minutes to mimic the step of virus lysis. Then both samples were placed into the oven with a pre-set temperature of $\sim 68{ }^{\circ} \mathrm{C}$. The amplification of nucleic acid was tracked at different reaction time points $(0 \mathrm{~min}, 20 \mathrm{~min}, 30 \mathrm{~min}$, and 45 min) by taking out the samples for fluorescence detection and visual based turbidity detection, respectively. As shown in Figure 5B, the positive sample can be detected within 
$20 \mathrm{~min}$ (or even shorter time) through fluorescence under UV light, while turbidity difference was obvious after $45 \mathrm{~min}$ reaction. The weak fluorescent background from both samples at $\mathrm{t}=0 \mathrm{~min}$ may be ascribed to the use of $254 \mathrm{~nm}$ UV light as nucleic acids have a strong absorption at this UV wavelength. This study indicates that one-step, closedtube RT-LAMP can be realized by separating the sample solution from the RT-LAMP reaction reagents at the beginning for manufacturing purpose. Minimum involvement of the end-user was accomplished, endowing the feasibility to run RT-LAMP for nucleic acid detection at home. Although we only used RNA sample in the study due to limit access to resources, this procedure can be extended to direct use of virus sample if enzymatic lysis solution (containing thermal-labile proteinase $\mathrm{K}$ ) is used to replace water for lysing viruses, destroying RNase and releasing viral RNA (Figure 1). Currently proteinase $K$ containing lysis buffer is commercially available for this purpose with high efficiency. However, after virus lysis, the lysis buffer requires a high-temperature treatment step (e.g., $95{ }^{\circ} \mathrm{C}$ for 5 to $10 \mathrm{~min}$ ) to deactivate proteinase $\mathrm{K}$, which is typically thermal stable. Otherwise, proteinase $\mathrm{K}$ can digest enzymes such as reverse transcriptase/DNA polymerase in RT-LAMP reagents, thus significantly interfering subsequent isothermal amplification. However, such high temperature treatment is not compatible with those enzymes used in RT-LAMP. Consequently, it is challenging to combine these two steps (enzymatic lysis and RT-LAMP reaction) in a one-tube platform. As aforementioned, more handling steps disfavor home use of RT-LAMP considering the fact that end-users at home typically lack training of laboratorial skills. In order to achieve "true" one-step, closed-tube RT-LAMP reaction, one solution is to use thermal-labile proteinase $\mathrm{K}$ (e.g., the one from New England Biolabs) in lysis buffer. Thermal-labile proteinase $K$ is inactivated at $55^{\circ} \mathrm{C}$ (a temperature lower than RT-LAMP temperature), thus allowing onestep, closed-tube RT-LAMP feasible. As shown in Figure 1, after loading the virus sample (e.g., through swab swirling) and virus lysis/release of viral RNA, the test tube is then placed into a pre-heated oven (e.g., $68^{\circ} \mathrm{C}$ in this study), which inactivates thermal-labile proteinase $\mathrm{K}$. Then following the same procedures of flip-and-swing enabled mixing and RT-LAMP reaction, one can realize "true" one-step, closed-tube RT-LAMP in an oven with minimum involvement of the end-user. 


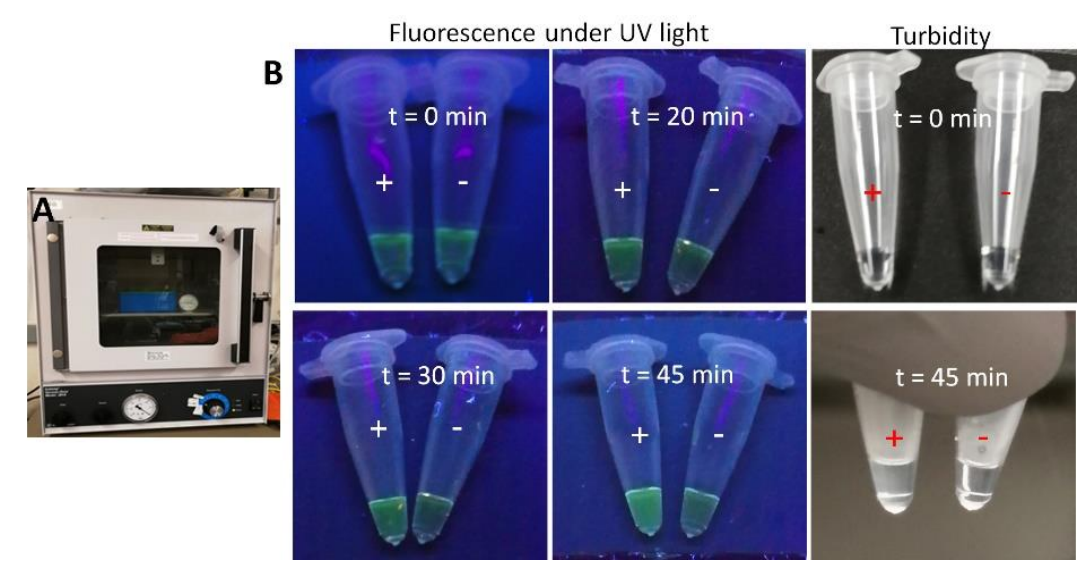

Figure 5. A vacuum oven (A) without digital temperature control for running one-step, closed-tube RT-LAMP for the detection through both turbidity and fluorescence (B).

The results above demonstrate an innovative and rapid transformative technology to accomplish a low-cost, user-friendly home-use nucleic acid (RNA or DNA) detection strategy through a simple, one-step, closed-tube RT-LAMP in an Oven. All operations are simple and can be completed at residential homes using existing tools/devices. It only requires minimum involvement of end-users. Also, it does not cause any additional cost to the end-user except the cost of test kits, while allowing the operation by end-users themselves. To run RT-LAMP (or LAMP) in an Oven (or Range Oven) has unprecedented merits to surpass PCR machine based or water-bath based RT-LAMP (or LAMP) methods as it allows the detection without adding extra cost to the residents, while onestep, closed-tube procedure with minimum involvement allows home use without introducing the difficulty to end-users who typically have no laboratory experience. In addition, as all work can be conducted using available tool at home such as Range Oven and the detection of turbidity by naked eye, the capital cost for end-users is minimized and can be treated as zero. Also, the test kits can be used at home which will be fully conducted by end-users themselves following the instruction, so there is no additional operation cost associated with the tests. For each test, the major cost comes from the detection kits, including two items - swab and one RT-LAMP tube including all reagents. Table 3 indicates that the estimated total cost per test in the final product format could be as low as $\$ 7$ per test. 
Table 3. Estimated total cost per test

\begin{tabular}{|c|c|c|}
\hline Items & $\begin{array}{l}\text { Unit Cost } \\
\text { per test }\end{array}$ & Justification \\
\hline 1. Swab & $\sim \$ 0.15$ & $\begin{array}{l}\text { PurFlock Ultra Flocked Swab, } 1000 / \text { case, } \\
\$ 134.99 \text {, plus tax }\end{array}$ \\
\hline $\begin{array}{l}\text { 2. RT-LAMP tube with } \\
\text { all reagents in } \\
\text { lyophilization powder } \\
\text { format }\end{array}$ & $\sim \$ 6.5$ & $\begin{array}{l}\text { LavaLAMP TM RNA Component Kit with Dye, } \$ 298 \\
\text { for } 500 \text { reactions; plus the cost of tube, LAMP } \\
\text { primers, dNTP mix, and thermal-liable proteinase } \\
\text { K; lyophilization cost; and packaging cost }\end{array}$ \\
\hline Total Cost per test & $\sim \$ 7$ & \\
\hline
\end{tabular}

\section{Conclusion}

This study investigated the feasibility to run one-step, closed-tube RT-LAMP for RNA detection at home. By employing kitchen range oven's "Keep Warm" function as the heating source, RT-LAMP can be successfully conducted in home-use Range Oven without sacrificing the sensing performance. Furthermore, by pre-loading the concentrated RT-LAMP reaction reagents and sample collection solution to the cap cavity and the bottom of a PCR tube, respectively, one-step, closed-tube RT-LAMP can be realized in an oven, which only requires the end-user to open the tube once for loading the target sample at the beginning. Loading the target sample can be accomplished using either swab swirling or direct pipetting. The mixing of the target sample and RT-LAMP reaction reagents in PCR tube are realized by a motion of sudden stop of swinging. Considering the desperate need of increasing the screening capacity for containing COVID-19 pandemic, this home-use RT-LAMP methodology offers a new avenue. As all operations are simple and can be completed with minimum involvement of end-users at residential homes using existing tools/devices, it will not result in any additional cost to the end-user except the cost of test kits. As the test can be carried out at individual home, the testing capacity is unlimited. Therefore, it has the potential to screen a large US population within one day as all tests can be simultaneously conducted at each individual family without the need of skilled personnel. The developed method is also appropriate to the detection of any infectious disease related nucleic acid markers. Therefore, it could play an important role in combatting the outbreaks of pandemics nowadays as well as in future. 


\section{Acknowledgement}

We greatly appreciate the support from the University of Connecticut.

\section{References}

1. Notomi, T.; Okayama, H.; Masubuchi, H.; Yonekawa, T.; Watanabe, K.; Amino, N.; Hase, T., Loop-mediated isothermal amplification of DNA. Nucleic acids research 2000, 28, e63-e63.

2. Poon, L. L.; Leung, C. S.; Tashiro, M.; Chan, K. H.; Wong, B. W.; Yuen, K. Y.; Guan, Y.; Peiris, J. S., Rapid detection of the severe acute respiratory syndrome (SARS) coronavirus by a loop-mediated isothermal amplification assay. Clinical chemistry 2004, 50, 1050-1052.

3. Iwamoto, T.; Sonobe, T.; Hayashi, K., Loop-mediated isothermal amplification for direct detection of Mycobacterium tuberculosis complex, M. avium, and $M$. intracellulare in sputum samples. Journal of clinical microbiology 2003, 41, 2616-2622.

4. Endo, S.; Komori, T.; Ricci, G.; Sano, A.; Yokoyama, K.; Ohori, A.; Kamei, K.; Franco, M.; Miyaji, M.; Nishimura, K., Detection of gp43 of Paracoccidioides brasiliensis by the loop-mediated isothermal amplification (LAMP) method. FEMS microbiology letters 2004, 234, 93-97.

5. Shao, Y.; Zhu, S.; Jin, C.; Chen, F., Development of multiplex loop-mediated isothermal amplification-RFLP ( $\mathrm{mLAMP}-\mathrm{RFLP}$ ) to detect Salmonella spp. and Shigella spp. in milk. International journal of food microbiology 2011, 148, 75-79.

6. Xie, Z.; Tang, Y.; Fan, Q.; Liu, J.; Pang, Y.; Deng, X.; Xie, Z.; Peng, Y.; Xie, L.; Khan, M. I., Rapid detection of Group I avian adenoviruses by a Loop-mediated isothermal amplification. Avian diseases 2011, 55, 575-579.

7. Enomoto, Y.; Yoshikawa, T.; Ihira, M.; Akimoto, S.; Miyake, F.; Usui, C.; Suga, S.;

Suzuki, K.; Kawana, T.; Nishiyama, Y., Rapid diagnosis of herpes simplex virus infection by a loop-mediated isothermal amplification method. Journal of clinical microbiology 2005, 43, 951-955. 
8. Peng, Y.; Xie, Z.; Liu, J.; Pang, Y.; Deng, X.; Xie, Z.; Xie, L.; Fan, Q.; Feng, J.; Khan, M. I., Visual detection of H3 subtype avian influenza viruses by reverse transcription loop-mediated isothermal amplification assay. Virology journal 2011, 8, 1.

9. Nemoto, M.; Imagawa, H.; Tsujimura, K.; Yamanaka, T.; Kondo, T.; Matsumura, T., Detection of equine rotavirus by reverse transcription loop-mediated isothermal amplification (RT-LAMP). Journal of Veterinary Medical Science 2010, 72, 823-826.

10.Xie, Z.; Fan, Q.; Liu, J.; Pang, Y.; Deng, X.; Xie, Z.; Liji, X.; Khan, M. I., Reverse transcription loop-mediated isothermal amplification assay for rapid detection of Bovine Rotavirus. BMC veterinary research 2012, 8, 1.

11.Fan, Q.; Xie, Z.; Xie, L.; Liu, J.; Pang, Y.; Deng, X.; Xie, Z.; Peng, Y.; Wang, X., A reverse transcription loop-mediated isothermal amplification method for rapid detection of bovine viral diarrhea virus. Journal of virological methods 2012, 186, 4348.

12. Lee, D.; Kim, E. J.; Kilgore, P. E.; Kim, S. A.; Takahashi, H.; Ohnishi, M.; Anh, D. D.; Dong, B. Q.; Kim, J. S.; Tomono, J., Clinical evaluation of a loop-mediated isothermal amplification (LAMP) assay for rapid detection of Neisseria meningitidis in cerebrospinal fluid. PloS one 2015, 10, e0122922.

13. Francois, P.; Tangomo, M.; Hibbs, J.; Bonetti, E.-J.; Boehme, C. C.; Notomi, T.; Perkins, M. D.; Schrenzel, J., Robustness of a loop-mediated isothermal amplification reaction for diagnostic applications. FEMS Immunology \& Medical Microbiology 2011, 62, 41-48.

14. Kaneko, H.; lida, T.; Aoki, K.; Ohno, S.; Suzutani, T., Sensitive and rapid detection of herpes simplex virus and varicella-zoster virus DNA by loop-mediated isothermal amplification. Journal of clinical microbiology 2005, 43, 3290-3296.

15. Nagamine, K.; Hase, T.; Notomi, T., Accelerated reaction by loop-mediated isothermal amplification using loop primers. Molecular and cellular probes 2002, 16, 223-229.

16. Iseki, H.; Alhassan, A.; Ohta, N.; Thekisoe, O. M.; Yokoyama, N.; Inoue, N.; Nambota, A.; Yasuda, J.; Igarashi, I., Development of a multiplex loop-mediated isothermal amplification (mLAMP) method for the simultaneous detection of bovine Babesia parasites. J Microbiol Meth 2007, 71, 281-287. 
17. Yamazaki, W.; Mioulet, V.; Murray, L.; Madi, M.; Haga, T.; Misawa, N.; Horii, Y.; King, D. P., Development and evaluation of multiplex RT-LAMP assays for rapid and sensitive detection of foot-and-mouth disease virus. Journal of Virological Methods 2013, 192, 18-24.

18. Nie, K.; Qi, S.X.; Zhang, Y.; Luo, L.; Xie, Y.; Yang, M.J.; Zhang, Y.; Li, J.; Shen, H.; Li, Q.; Ma, X.J. Evaluation of a direct reverse transcription loop-mediated isothermal amplification method without RNA extraction for the detection of human enterovirus 71 subgenotype C4 in nasopharyngeal swab specimens. PLOS One 2012, 7, e52486.

19. Mohamed El-Tholoth, Haim H. Bau, Jinzhao Song. A Single and Two-Stage, ClosedTube, Molecular Test for the 2019 Novel Coronavirus (COVID-19) at Home, Clinic, and Points of Entry. Preprint, 2020, ChemRxiv.

20. Bo Dai, Ziao Jiao, Lulu Zheng, Hunter Bachman, Yongfeng Fu, Xinjun Wan, Yule Zhang, Yu Huang, Xiaodian Han, Chenglong Zhao, Tony Jun Huang, Songlin Zhuang, Dawei Zhang. Colour compound lenses for a portable fluorescence microscope. Light Science and Applications 2019, 8, article \# 75.

21. Luo, S.; Xie, Z.; Xie, L.; Liu, J.; Xie, Z.; Deng, X.; Huang, L.; Huang, J.; Zeng, T.; Khan, M. I., Reverse-transcription, loop-mediated isothermal amplification assay for the sensitive and rapid detection of $\mathrm{H} 10$ subtype avian influenza viruses Influenza viruses. Virology Journal 2015, 12, 145. 